\title{
Lung volume reduction surgery in chronic obstructive pulmonary disease
}

\author{
L Davies, P M A Calverley \\ Aintree Chest Centre, Fazakerley Hospital, Liverpool, UK
}

Introductory article

Bilateral pneumectomy (volume reduction) for chronic obstructive pulmonary
disease

JD Cooper, EP Trulock, AN Triantafillou, GA Patterson, MS Pohl, PA Deloney, RS Sundaresan, CL Roper

We undertook surgical bilateral lung volume reduction in 20 patients with severe chronic obstructive pulmonary disease to relieve thoracic distention and improve respiratory mechanics. The operation, done through median sternotomy, involves excision of $20 \%$ to $30 \%$ of the volume of each lung. The most affected portions are excised with the use of a linear stapling device fitted with strips of bovine pericardium attached to both the anvil and the cartridge, to buttress the staple lines and eliminate air leakage through the staple holes. Preoperative and postoperative assessment of results has included grading of dyspnoea and quality of life, exercise performance, and objective measurements of lung function by spirometry and plethysmography. There has been no early or late mortality and no requirement for immediate postoperative ventilatory assistance. Follow-up ranges from 1 to 15 months (mean 6.4 months). The mean forced expiratory volume in 1 second has improved by $82 \%$ and the reduction in total lung capacity, residual volume, and trapped gas has been highly significant. These changes have been associated with marked relief of dyspnoea and improvement in exercise tolerance and quality of life. Although the follow-up period is short, these preliminary results suggest that bilateral surgical volume reduction may be of significant value for selected patients with severe chronic obstructive pulmonary disease. (J Thorac Cardiovasc Surg 1995;109:106-19)

The management of chronic obstructive pulmonary disease (COPD) is largely a medical problem, a fact reflected in recent international treatment guidelines. ${ }^{12}$ However, various surgical approaches to treatment have been devised, usually aimed either at improving respiratory muscle function by changes in thoracic cage volume or modifications of the underlying lung mechanics. These have included procedures as diverse as chondrectomy to mobilise the chest wall, autonomic and peripheral chemoreceptor denervation, and attempts to limit expiratory airway closing using Goretex, rectus sheath, fascia lata and plastic prostheses. These approaches have met with little success and have been abandoned. ${ }^{3}$ Only two forms of surgery are now generally practised for patients with COPD - namely, bullectomy and lung transplantation. Although the latter procedure produces dramatic improvement in symptoms and exercise capacity, its use is limited by the availability of suitable donor organs, competition from patients with other lung diseases (who are often younger), and a recognition that chronic rejection and especially the development of obliterative bronchiolitis limits median survival to about three years. ${ }^{4}$ The growing number of disabled patients with COPD waiting for transplantation led the St Louis group of surgeons to reconsider old options and revisit a procedure now known as lung volume reduction surgery (LVRS). ${ }^{5} \mathrm{Al}-$ ternative approaches using thoracoscopic laser treatment to contract overexpanded areas of lung have been developed on the West Coast of America. In the last two years these procedures have become so widespread as to alarm US medical insurers who have asked for a moratorium on their use until further evidence of their effectiveness is available. Before reviewing the data that led to this remarkable position, it is instructive to consider what happened when bullectomy was originally developed as a procedure to improve symptoms in patients with COPD.

\section{Surgery for bullae}

Bullae have been defined as emphysematous spaces larger than $1 \mathrm{~cm}$ in diameter in the inflated state. ${ }^{6}$ Several "types" are recognised with type 1 bullae arising in the lungs of non-smokers whilst types 2 and 3 appear to be an exaggeration of the underlying panacinar or centriacinar emphysema. ${ }^{7}$ In this respect the use of the terms "types 3 and 4 bullae" by some surgeons involved 


\section{Patients most likely to benefit from surgery for bullae \\ Those with \\ - symptomatic and rapidly progressive dyspnoea \\ - severe, but localised disease, with bullae occupying at least $33 \%$ (and in some reports at least $50 \%$ ) of one hemithorax \\ - definite radiological evidence of displaced adjacent lung tissue which is usually obtained by CT scanning \\ - evidence of regional imbalance of perfusion defined by quantitative $\dot{\mathrm{V}} / \mathbf{Q}$ scanning \\ - minimal inflammatory component to the disease process - that is, little in the way of chronic suppurative bronchitis \\ - no electrocardiographic evidence of right ventricular failure \\ - normal or only slightly raised $\mathrm{PaCO}_{2}$ preoperatively}

Box 1

in LVRS (for example, Wakabayashi) is different from the rest of the literature. In practice, the type of bulla is less important than its functional impact, and surgery is usually considered when a bulla occupies at least one third of the lung. Detailed reviews of the pathophysiology and results of surgery for bullous lung disease are available. ${ }^{8}$ Several surgical techniques have been developed to remove the dominant bulla allowing underlying compressed and potentially functioning lung to re-expand. A consensus has now emerged about the most appropriate patients to treat in this way (box 1).

Typical results of surgery are those of Wesley et al ${ }^{9}$ who reported a follow up of 2-8 years in 11 long term survivors from an initial group of 14 patients with COPD. All showed improvements of $19-225 \%$ in baseline forced expiratory volume in one second $\left(\mathrm{FEV}_{1}\right)$ with a mean change of 0.75 litres (range $0.05-2$ litres). In patients with even lower baseline $\mathrm{FEV}_{1}$ values down, for example, to 0.5 litres, the Brompton modification of the Monaldi technique of intracavity drainage has been found to be relatively safe ( $18 \%$ mortality!). ${ }^{10}$ It is interesting that the earliest series of LVRS was abandoned because it was associated with a $16 \%$ mortality. ${ }^{11}$ This pattern of incomplete reporting of follow up data and retrospective analysis established for bullectomy has so far been repeated with the newer procedures now being developed. Nonetheless, there are good data to suggest that bullectomy in suitably selected patients can have sustained benefit. ${ }^{12}$ Gaensler et $a l^{13}$ offer the largest single centre experience and have emphasised the importance of avoiding patients with chronic infection and, in their case, choosing particularly large bullae to resect. This group was opposed to the resection of any healthy lung as they felt this would diminish the gas exchanging ability even further. Their views were important in curtailing the earlier development of LVRS, despite the fact that the mortality of the procedure had fallen substantially as more patients were being treated.

\section{Pathophysiological considerations of bullae}

In most cases of COPD the predominant cause of airways obstruction is not the large airways - where changes of chronic bronchitis occur ${ }^{14}$ - but the smaller airways of less than $2 \mathrm{~mm}$ in diameter where a combination of fibrosis and inflammation restricts airflow. In addition, coexisting emphysema reduces pulmonary elastic recoil and loss of alveolar attachment means that airway collapse occurs prematurely. The relative importance of these two processes - small airways disease and emphysema - continues to be debated, with some groups believing that emphysema is itself physiologically unimportant ${ }^{1516}$ while others have related the clinical pattern of particular types of emphysema to either small airways disease or a reduction in elastic recoil. ${ }^{17}$ Bullae have always been considered a special case where particularly weakened areas of the lung have broken down and enlarged, relatively rapidly, leading to the collapse/compression of adjacent lung. ${ }^{18}$ The resulting space ventilates so poorly that it adds little to the total dead space and so does not influence gas exchange. Whether or not bullae are under positive pressure during spontaneous breathing remains uncertain. ${ }^{19}$ However, when their volume is sufficient, their removal/obliteration is seen to improve gas exchange and reduce pulmonary overinflation in much the same way as does draining an extrapleural pneumothorax.

Since most patients with severe COPD do not have giant bullae, surgery can have only a limited role. However, not all surgeons have accepted this and, in the 1950s, Otto Brantigan suggested that the normal circumferential pull on the airways was lost in emphysema and might be restored by downsizing the lungs. $\mathrm{He}$ emphasised that his operation was not designed to remove pathological tissue but was directed at the "restoration of a normal physiologic principle". Lung volumes were reduced by a "clamp and suture" method with vagotomy which had the theoretical benefit of diminishing sputum retention. His results were reported on 26 sequential patients, five of whom died. Patients underwent unilateral thoracotomy with the contralateral side being operated on at least three months later. Most of the benefit followed the first operation. The initial postoperative mortality was high at $16 \%$, largely as a result of persisting air leaks, and objective improvement was hard to demonstrate. At this stage it appeared that conventional physiological wisdom was correct and only bullae were worth resecting.

\section{Lung volume reduction surgery: the modern approach}

By the late 1980s Cooper and colleagues working in St Louis had developed the procedure of single lung transplantation for emphysema. ${ }^{20}$ They were initially worried that the transplanted lung would be much smaller than the thoracic cavity into which it was transplanted, but this did not prove to be a problem as the configuration of the chest wall rapidly adapted to the new smaller volume. Moreover, they had found that it was possible to ventilate even patients with severe emphysema satisfactorily through one lung alone. As their list of patients awaiting transplantation grew, they looked for alternatives which might give symptomatic benefit and reconsidered the ideas of Brantigan. Their selection criteria are listed in table 1 . They developed a robust battery of imaging and physiological assessments before and afterwards which has led to more rigorous data collection than previously (table 2). Their initial report in 1995 described this procedure in 20 patients with severe COPD who were selected on the basis of a distended thorax, predominantly upper lobe disease as defined by CT scanning, and significant functional limitation despite undergoing a course of pulmonary rehabilitation. Fourteen patients required supplemental oxygen on exercise and five were using oxygen continuously at rest. Two were already on the lung transplant waiting list. All underwent median sternotomy 


\section{Table 1 Selection criteria for LVRS $^{5}$}

Indications

- significant functional limitation despite maximum medical treatment

heterogeneous distribution of emphysematous disease

- marked thoracic distention

Relative contraindications

- significant hypercapnia $\left(\mathrm{PaCO}_{2}>50 \mathrm{~mm} \mathrm{Hg}\right)$

ventilation/perfusion scan showing a mottled pattern, uniformly affecting both lungs

Absolute contraindications

- severe kyphoscoliosis

- pulmonary hypertension with mean pulmonary artery pressure

$>35 \mathrm{~mm} \mathrm{Hg}$ or systolic pulmonary artery pressure $>45 \mathrm{~mm} \mathrm{Hg}$

- significant coronary artery disease

previous thoracotomy or pleurodesis

longstanding history of asthma, bronchiectasis

- chronic bronchitis with production of purulent sputum

current smoker

\section{Table 2 Preoperative and postoperative assessments ${ }^{5}$}

\begin{tabular}{|c|c|c|}
\hline Investigation & Preoperative & $\begin{array}{l}\text { Postoperative } \\
\text { (at } 1,3,6 \text { and } \\
12 \text { months) }\end{array}$ \\
\hline $\begin{array}{l}\text { Posteroanterior and lateral chest } \\
\text { radiograph (in inspiration and } \\
\text { expiration) } \\
\text { Chest CT scan } \\
\text { Quantitative V/Q scan } \\
\text { Lung volume measurements with } \\
\text { body box plethysmography and } \\
\text { nitrogen washout } \\
\text { Resting nuclear ventriculogram } \\
\text { (and, if abnormal, catheterisation } \\
\text { of the left, right or both sides of } \\
\text { the heart) } \\
\text { Arterial blood gases } \\
\text { Standardised } 6 \text { minute walk } \\
\text { Requirement for supplementary } \\
\text { oxygen on exertion } \\
\text { Assessment of dyspnoea: } \\
\text { MRC dyspnoea scale } \\
\text { dyspnoea index } \\
\text { Assessment of quality of life: } \\
\text { Nottingham Health Profile } \\
\text { SF-36 }\end{array}$ & $\begin{array}{l}\checkmark \\
\checkmark \\
\checkmark \\
\checkmark\end{array}$ & $\begin{array}{l}\sqrt{ } \\
\sqrt[J]{ } \\
\sqrt{ }\end{array}$ \\
\hline
\end{tabular}

and none required cardiopulmonary bypass. The goal was to reduce lung volume by $20-30 \%$ and they used the fact that the healthier areas of the lung underwent reabsorption atelectasis more readily than those with a poorer blood supply to select out the principal areas for excision. They overcame the problem of persistent air leaks by using strips of bovine pericardium to buttress the stapling line. There were no early or late deaths in the series and they were able to reduce the hospital stay from 20 days for the first 10 patients to 10 days for the second 10, demonstrating a clear learning effect. However, four patients had to undergo re-exploration subsequently, three for air leaks and the fourth because of local bleeding. The results of the surgery in terms of physiological and functional assessments are shown in table 3.

\section{Thoracoscopic laser pneumoplasty}

An alternative approach with much the same intent has been developed using laser treatment rather than more conventional excisional surgery. Initially, the $\mathrm{CO}_{2}$ laser was used to excise areas of lung containing bullae in patients who were otherwise at high risk. The first reports suggested that it was possible to improve $\mathrm{FEV}_{1}$, vital capacity, and exercise tolerance, ${ }^{21}$ but the post-
Table 3 Physiological and functional assessments before $(n=20)$ and after surgery (at six months $(n=8)$ or earlier $(n=12)$ if six months not reached $)^{5}$

\begin{tabular}{|c|c|c|c|}
\hline & $\begin{array}{l}\text { Pre- } \\
\text { operative }\end{array}$ & $\begin{array}{l}\text { Post- } \\
\text { operative }\end{array}$ & $\begin{array}{l}p \\
\text { value }\end{array}$ \\
\hline Mean FEV 1 in litres (\% & $0.77(25)$ & $1.4(44)$ & $<0.001$ \\
\hline $\begin{array}{l}\text { Mean FVC in litres (\% predicted) } \\
\text { TLC in litres (\% predicted) } \\
\mathrm{RV} \text { in litres }(\% \text { predicted) } \\
\mathrm{Trapped} \text { gas }(\mathrm{l}) \\
\text { Mean } \mathrm{PaO}_{2} \text { on air ( } \mathrm{mm} \mathrm{Hg} \text { )** } \\
\text { Mean } \mathrm{PacO}_{2} \text { on air }(\mathrm{mm} \mathrm{Hg}) \\
\text { Mean pulmonary artery pressure }\end{array}$ & $\begin{array}{l}2 \cdot 2(56) \\
8 \cdot 5(140) \\
5 \cdot 9(228) \\
2 \cdot 4 \\
64 \\
40 \\
23(5 \cdot 1)\end{array}$ & $\begin{array}{l}2.8(73) \\
6 \cdot 6(110) \\
3.6(171) \\
1.2 \\
70 \\
39\end{array}$ & $\begin{array}{l}<0.05 \\
<0.001 \\
<0.001 \\
<0.001 \\
<0.05 \\
\text { NS }\end{array}$ \\
\hline $\begin{array}{l}\text { No. of patients requiring } \\
\text { supplemental oxygen on } \\
\text { exercise }\end{array}$ & 14 & 4 & \\
\hline $\begin{array}{l}\text { Mean } 6 \text { minute walk distance } \\
\text { (feet) } \\
\text { Dyspnoea: }\end{array}$ & $\sim 1200$ & $\sim 1600$ & \\
\hline $\begin{array}{l}\text { MRC scale } \\
\text { Dyspnoea index } \\
\text { Quality of life } \\
\text { Q*** }\end{array}$ & $\begin{array}{l}2.9 \\
1.2\end{array}$ & $\begin{array}{l}0.8 \\
+2\end{array}$ & $\leq 0.05$ \\
\hline
\end{tabular}

$\mathrm{FEV}_{1}=$ forced expiratory volume in one second; $F V C=$ forced vital capacity; TLC=total lung capacity; RV = residual volume; NS = not significant

* Trapped gas calculation is the difference between TLC as measured by plethysmography and that measured by nitrogen washout technique.

** Two patients receiving continuous oxygen preoperatively were excluded.

*** Data presented in different forms, but significant improvement postoperatively.

Table 4 Comparison between mean (SD) preoperative and postoperative data

\begin{tabular}{|c|c|c|c|c|}
\hline Variable & $\begin{array}{l}\text { No. of } \\
\text { pairs }\end{array}$ & $\begin{array}{l}\text { Pre- } \\
\text { operative }\end{array}$ & $\begin{array}{l}\text { Post- } \\
\text { operative }\end{array}$ & $\begin{array}{l}p \\
\text { value }\end{array}$ \\
\hline $\begin{array}{l}\mathrm{O}_{2}(\mathrm{~mm} \mathrm{Hg}) \\
\mathrm{CO}_{2} \text { (mm Hg) } \\
\mathrm{MT} \text { (min) } \\
\mathrm{IC} \text { (\% predicted) } \\
\mathrm{V}_{1} \text { (\% predicted) } \\
\mathrm{V}_{1} / \mathrm{FVC} \text { (\% predicted) } \\
\mathrm{AW} \text { (\% predicted) } \\
\mathrm{V} \text { (\% predicted) } \\
\mathrm{LC} \text { (\% predicted) } \\
\text { CO (\% predicted) }\end{array}$ & $\begin{array}{r}96 \\
91 \\
81 \\
203 \\
202 \\
185 \\
55 \\
125 \\
118 \\
123\end{array}$ & $\begin{array}{c}65.0(11.6) \\
41.6(7.3) \\
4.6(3.2) \\
55.8(18.2) \\
23.6(10.8) \\
33.6(9.8) \\
634.1(194.7) \\
201.0(59.0) \\
112.2(20.4) \\
23.6(12.6)\end{array}$ & $\begin{array}{c}66.0(10.8) \\
40.7(6.5) \\
8.0(4.9) \\
67.4(20.1) \\
31.0(9 \cdot 6) \\
34.1(9.5) \\
527.2(239.6) \\
174.9(62.1) \\
106.8(23.3) \\
33.7(16.7)\end{array}$ & $\begin{array}{l}0.360 \\
0.107 \\
0.001 \\
0.001 \\
0.001 \\
0.243 \\
0.001 \\
0.001 \\
0.011 \\
0.001\end{array}$ \\
\hline \multicolumn{5}{|c|}{$\begin{array}{l}\text { TLCO = carbon monoxide transfer factor; } \mathrm{FEV}_{1}=\text { forced expiratory } \\
\text { volume in one second; } \mathrm{FVC}=\text { forced vital capacity; } \mathrm{P} \mathrm{CO}_{2}=\text { carbon } \\
\text { dioxide tension; } \mathrm{PO}_{2}=0 x y g \text { ox tension; } \mathrm{RAW}=\text { airway resistance; } \\
\mathrm{RV}=\text { residual volume; } \mathrm{TLC}=\text { total lung capacity; } \mathrm{TMT}=\text { treadmill } \\
\text { test. } \\
\text { Modified from Wakabayashi et al. } .^{23}\end{array}$} \\
\hline
\end{tabular}

operative mortality rate was $9 \%$ and again persistent postoperative air leakage was a particularly serious problem. Little and colleagues ${ }^{22}$ used an Nd:YAG laser to treat the surfaces of the lungs and relied on the fact that the lung that remained inflated - that is, the most affected areas - would absorb most of the energy of the laser and as a result contraction and scarring would be confined to the most damaged areas. Their initial report was of a mixture of patients who received this treatment together with some who had also undergone bullectomy. As with other series, the surgery had been a mixture of thoracoscopy and sternotomy incisions depending upon the presence of adhesions.

Wakabayashi and colleagues have modified their treatment protocol and have reported what is much the largest series of cases undergoing LVRS. ${ }^{23}$ Representative data before and after this surgery are shown in table 4. However, as has been pointed out elsewhere ${ }^{24}$ this series is significantly flawed because of the incompleteness of the objective follow up measurement 
and the patient questionnaire data. Whilst most of the patients in this series have undergone unilateral treatment, some have been treated bilaterally and it is difficult to determine from information available how much benefit accrues from each approach.

One important question is the role of LVRS in patients who would otherwise be eligible for lung transplantation at a later date. So far, two cases using this procedure as a bridge to lung transplantation have been reported. In the first case, a 60 year old man with an $\mathrm{FEV}_{1}$ of only $16 \%$ predicted was treated with video assisted thoracic surgery lung volume reduction to help control his breathlessness. This provided significant symptomatic relief together with some improvement in lung function. He underwent an uncomplicated single lung transplant on the same side as that which had been treated some 17 months after his original procedure. A similar sequence of procedures was undertaken in a 50 year old woman with severe COPD who was transplanted four months after LVRS. ${ }^{25}$

\section{Pathophysiological considerations of lung volume reduction surgery}

The improvement in $\mathrm{FEV}_{1}$ after LVRS is comparable to that seen in corticosteroid responsive patients with COPD after two weeks of high dose prednisolone, ${ }^{26}$ whilst the reported improvement in six minute walking distance is up to four times greater than that produced by inhaled bronchodilators such as $\beta$ agonists or anticholinergics. ${ }^{27} 28$ Clearly, this is a procedure which offers the prospect of substantial improvement despite the excision of up to $30 \%$ of the lung volume. One pointer to the possible mechanisms of this is the disparity between the improvement in the $\mathrm{FEV}_{1}$ and that in the self paced walking test. The $F E V_{1}$ in patients with COPD is now recognised to be a poor predictor of self paced walking distance ${ }^{29}$ and is not as accurate a marker of maximum minute ventilation as it is in normal subjects, ${ }^{30}$ principally because of the increased importance of inspiratory muscle strength as an independent determinant of exercise performance in COPD. ${ }^{31}$ Other tests of lung mechanics are poorly related to perceived breathlessness although there are data to show that swings in pleural pressure are important predictors of the intensity of breathlessness at rest and during carbon dioxide rebreathing in normal subjects and those with COPD. ${ }^{32-34}$ More recent data have shown that dynamic hyperinflation at rest, and particularly during exercise, is closely related to symptom intensity in both COPD and asthma. ${ }^{35}$ This process occurs when there is insufficient time for the lungs to empty before the next inspiration begins, and is particularly likely in those patients with COPD who adopt a rapid shallow breathing pattern to minimise inspiratory discomfort. Moreover, this increase in lung volume adds an additional elastic load to breathing and thus increases the overall work of breathing at rest.

Studies that have attempted to explain the benefit of lung volume reduction are in short supply, but preliminary data have been presented which suggest that these newly recognised mechanisms of disability in COPD are being influenced by the surgery. Dr O'Donnell from Kingston, Ontario, speaking at the 1995 American Thoracic Society meeting, described a small number of patients treated with LVRS who experienced dramatic reductions in the degree of dynamic hyperinflation after the operation. Studies from Vienna by Professor Kleptko and colleagues found that the work of breathing and the degree of intrinsic positive expiratory pressure (an indirect measure of lung hyperinflation) in eight patients were reduced immediately, and at three and six months after surgery. Further studies, particularly of gas exchange, are clearly needed before other mechanisms relevant to explaining these benefits can be excluded. Nonetheless, successful LVRS supports the argument that emphysema does make an important contribution to the symptoms of patients with COPD and to their accompanying airflow limitation.

\section{Are the benefits sustained?}

Whilst the immediate results of treatment are undoubtedly impressive, the question arises as to how long these improvements will last. At present follow up data are limited but, as the number of procedures reported is escalating rapidly, this is soon likely to change. Unfortunately, relatively few investigators have adopted the robust assessment procedure reported in table 2 which is certainly necessary if any new operation is to be evaluated properly. Moreover, it is not clear how representative or complete are the series of patients being reported compared with the total number of procedures performed. Variations in operative technique and patient selection further complicate this assessment. There are also significant differences between centres in the role
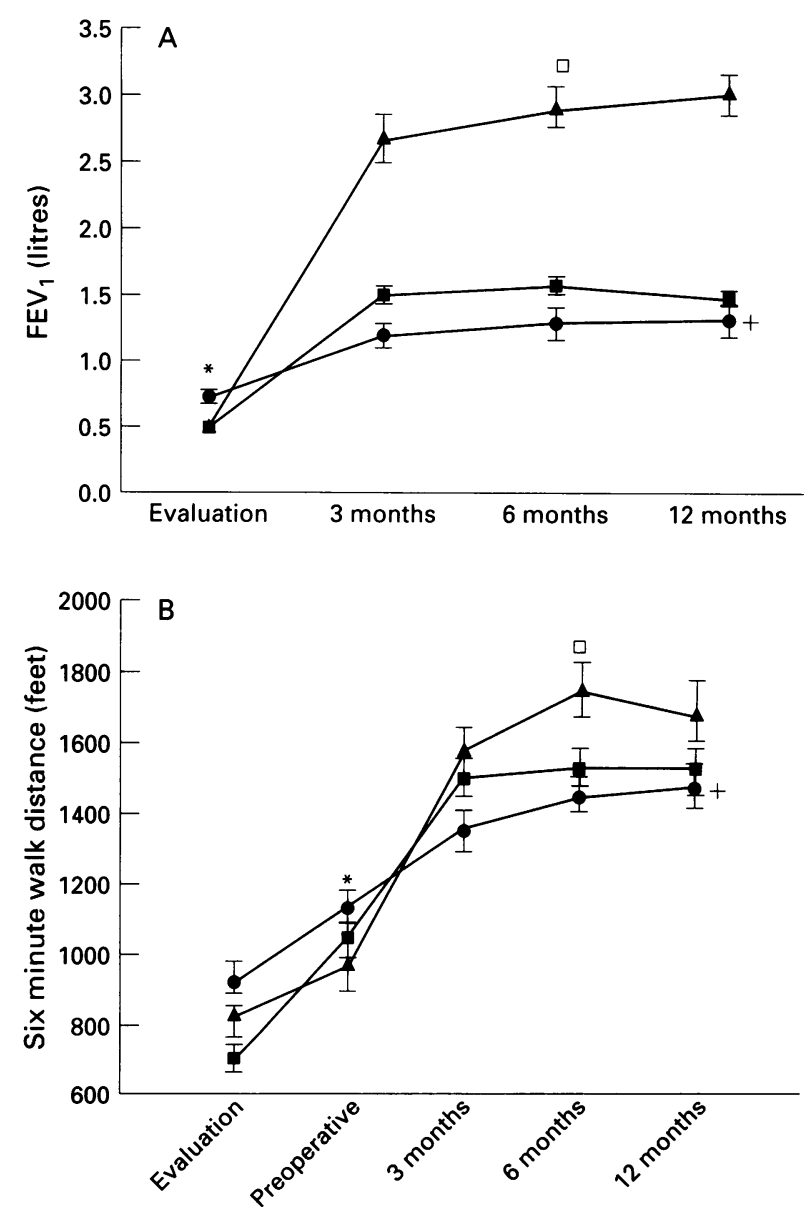

Figure 1 (A) FEV, and (B) six minute walk distance before and after volume reduction (VR, O), single lung

transplantation (SLT, $\square$ ), and bilateral lung transplantation $(B L T, \Delta)$. (A) at evaluation (*) VR versus $S L T, p<0.001 ; V R$ versus BLT, $p<0.001$. At six months ( $\square$ ) VR versus SLT, $p<0.001 ;$ VR versus $B L T, p<0.001$. (+) Evaluation versus VR at six months, $p<0.001$. (B) At evaluation (*) VR versus $S L T$, not significant; VR versus $B L T, p<0.05$. At six months ( $\square$ ) VR versus SLT, not significant; $V R$ versus $B L T, p<0.001 .(+)$ Evaluation versus $V R$ at six months, $p<0.001$.

Reproduced with permission from Gaissert et al. ${ }^{37}$ 
Future questions

1. Clinical questions

- How long does the benefit last?

- Is it influenced by patient selection?

- Does it change the underlying rate of decline of $\mathrm{FEV}_{1}$ ?

2. Patient selection

- Must patients meet all the present entry criteria?

- Which criteria best define future benefit?

- Should new criteria be developed?

- How important are asymptomatic areas of bronchiectasis?

- What is the safe upper level of $\mathrm{PaCO}_{2}$ ?

- Are small bullae always necessary?

- Do patients with predominantly basal emphysema do as well?

3. Technical issues

- Sternotomy versus thoracotomy

- Are laser and resectional surgery equivalent?

- Are bovine supported staples always necessary or can smaller endoscopic stapling be as effective?

- How long shoud patients spend in ITU?

- What is the role of prior pulmonary rehabilitation?

4. Mechanistic issues

- Does improvement in dynamic hyperinflation explain all the benefits of surgery?

- Are there relevant changes in respiratory muscle function?

- Is ventilation/perfusion mismatching important?

- Is the underlying type of emphysema important?

Box 2

of pulmonary rehabilitation. Thus, in St Louis the patients entered an intensive pulmonary rehabilitation course for a minimum of six weeks before operation, whilst in Pittsburgh rehabilitation was not included as an entry criterion before or even after surgery. The fact that all centres report improvement is encouraging, but it would be much more helpful if there were a standardised approach between two or three centres so that the particular components of treatment could be identified. The problems of research in general surgery clearly extend to the cardiothoracic field. ${ }^{36}$

The most complete follow up data published come from St Louis. ${ }^{37}$ Thirty three patients underwent LVRS (total mortality $3 \%$ ) and their functional improvements were compared postoperatively with those of 39 patients who underwent single lung transplantation (mortality $10 \cdot 2 \%$ ) and 25 in whom bilateral lung transplantation was performed (total mortality 16\%). The ages of the patients were similar but the disease severity before surgery, as expressed spirometrically, was greater in the transplanted patients (mean $\mathrm{FEV}_{1} 25 \%$ predicted in those who underwent LVRS compared with $15 \%$ predicted in those who underwent lung transplantation). More patients who had LVRS survived the year of follow up than did those who were transplanted, but they had shown a smaller increase in $\mathrm{FEV}_{1}$ and FVC (fig 1). However, the six minute walking distance had increased to similar levels by one year in both those who had volume reduction and single lung transplant patients, although the best results overall were achieved by those who survived bilateral lung transplantation.

Two further studies from other centres provide useful information about the relative efficacy of LVRS by stapling or the thoracoscopic method. Keenan et al reported that LVRS of one lung improved $\mathrm{FEV}_{1}$ by $20 \%$ or more of baseline in 25 of 40 patients available for study three months after surgery. ${ }^{38}$ They abandoned the $\mathrm{Nd}$ :YAG laser approach after six of the 10 patients they treated developed serious complications. McKenna et al reported a larger randomised trial of unilateral video assisted LVRS which compared Nd:YAG laser and stapling approaches. At six months the group mean changes in $\mathrm{FEV}_{1}$ were 0.09 litres after the laser treatment and 0.22 litres after the stapling procedure, with a significant postoperative morbidity due to air leakage in the former group. 39

Future questions

Inevitably, any new procedure raises a host of questions

\section{LEARNING POINTS}

* Until recently bullectomy has been the only effective surgical treatment in patients with stable COPD. Lung volume reduction surgery (LVRS) is a radical new approach which involves removal of both bullae and emphysematous lung tissue.

* Patients most likely to benefit are ex-smokers with significant functional limitation despite maximum medical therapy, together with little sputum production, a heterogeneous distribution of emphysematous disease, and marked thoracic distension.

* The physiological effects of the procedure are not fully understood. The goal is to reduce lung volume by $20-30 \%$ which probably improves pulmonary and chest wall mechanics at rest and during exercise.

* Initial results are very encouraging with considerable improvement in symptoms and functional capacity and a low mortality rate.

* However, follow up periods are short and patient reporting is selective, so whether these benefits are sustained and generalisible is unknown. There is no evidence that survival is improved.

* Until more complete data with longer follow up are available, the technique should be considered experimental. A large randomised trial is needed to clarify the appropriate role of this important new procedure. 
which only careful further studies can settle. A nonexhaustive list is offered in box 2. The crucial issues relate to the subsequent rate of loss of lung function and the relative risks and benefits of the procedure. Predictions on theoretical grounds suggest that a further decline in lung function is bound to occur, particularly if the predominant type of emphysema is panacinar, as studies of the lung mechanics of the emphysematous space suggest that this type of lesion has higher compliance than centriacinar disease. ${ }^{40}$ It is likely that LVRS will be a means of "buying time" rather than "curing" patients with significant emphysema. Should the early improvements be sustained, which is the case following successful bullectomy, ${ }^{12}$ then a gain of 0.5 litres in FEV $_{1}$ might lead to a 5-10 year benefit before the patients return to their initial level of symptomatology (assuming that rapid decliners lose lung function at $125 \mathrm{ml}$ per year and slow decliners at about $50 \mathrm{ml}$ per year). ${ }^{41}$ Given the likely reduction in health care consumed by patients who are less symptomatic and have evidence of objective improvement, this procedure could offer extremely good value for money. However, such a cost-benefit analysis, though essential in modern health care, must be undertaken in appropriately controlled circumstances.

At present the field of LVRS is rapidly expanding and it is likely that new data will be available even by the time this review is published. There is great enthusiasm by some who feel that the procedure need no longer be considered investigational, ${ }^{42}$ but we, like others assessing this field, ${ }^{43-45}$ believe it is essential that carefully constructed, prospective, randomised, controlled clinical trials are undertaken so that the procedure can be fully evaluated. It is ethical to delay introducing such a procedure for up to one year, as we know that the mortality experience is not likely to differ and so randomisation of patients to such a trial can easily be justified. Once the value of surgery is established, then aspects of technique and patient selection can be explored. If this is not done, then the current cost pressure on new developments in medical care is likely to restrict the application of what is both an intellectually exciting and clinically important new treatment option for patients with COPD.

1 American Thoracic Society. Standards for the diagnosis and care of patients with chronic obstructive pulmonary disease. Am $\mathcal{F}$ Respir Crit Care Med 1995;152:S77-120.

2 European Respiratory Society. Optimal assessment and management of chronic obstructive pulmonary disease (COPD). Eur Respir 7 1995; 8: $1398-420$.

3 Deslauriers J. A perspective on the role of surgery in chronic obstructive pulmonary disease (COPD). Chest Surg Clin North Am 1985;5:575602 .

4 Corris P. Lung transplantation. In: Calverley PMA, Pride N, eds. Chronic obstructive airways disease. London: Chapman and Hall, 1995: 561-70.

5 Cooper JD, Trulock EP, Triantafillou AN, Patterson GA, Pohl MS, Deloney PA, et al. Bilateral pneumectomy (volume reduction) for chronic obstructive pulmonary disease. $\mathcal{F}$ Thorac Cardiovasc Surg 1995; 109:106-19.

6 Ciba Foundation Guest Symposium. Terminology, definitions and classificaiton of chronic pulmonary emphysema and related conditions. Thorax 1959;14:286-99.

7 Reid L. In: The pathology of emphysema. London: Lloyd-Luke Ltd, 1967: 211.

8 Snider GL. Reduction pneumoplasty for giant bullous emphysema. Chest 1996;109:540-8.

9 Wesley JR, Macleod WM, Mullard KS. Evaluation and surgery of bullous emphysema. 7 Thorac Cardiovasc Surg 1972;63:945-55.

10 Venn GE, Williams PR, Goldstraw P. Intracavity drainage for bullous emphysematous disease: experience with the Brompton technique. Thorax 1988;43:998-1002.
11 Brantigan OC, Mueller E. Surgical treatment of pulmonary emphysema. Am Surg 1957;23:789-804

12 Pearson MG, Ogilvie C. Surgical treatment of bullae: late outcome. Thorax 1983;38:134-7.

13 Gaensler EA, Jederlinic PJ, Fitzgerald MX. Patient work-up for bullectomy. $\mathcal{F}$ Thorac Imaging 1986;1:75-93.

14 Jeffrey PK. Comparative morphology of the airways in asthma and chronic obstructive pulmonary disease. Am Rev Respir Dis 1994;150: S6-13.

15 Gelb AF, Schein M, Kuei J, Tashkin DP, Muller NL, et al. Limited contribution of emphysema in advanced chronic obstructive pulcontribution of emphysema in advanced chronic ob

16 Gelb AF, Hogg JC, Muller NL, Schein MJ, Kuei J, Tashkin DP, et al. Contribution of emphysema and small airways in COPD. Chest 1996; 109:353-9.

17 Kim WD, Eidelman DH, Izquierdo JL, Ghezzo H, Saetta MP, Cosio MG. Centrilobular and panlobular emphysema in smokers. Am Rev Respir Dis 1991;144:1385-90.

18 Morgan MDL. Bullous lung disease. In: Calverley PMA, Pride N, eds. Chronic obstructive pulmonary disease. London: Chapman and Hall, 1995: 547-59.

19 Morgan MDL, Edwards CW, Morris J, Matthews HR. Origin and behaviour of emphysematous bullae. Thorax 1989;44:533-8.

20 Kaiser LR, Cooper JD, Trulock EP Pasque MK, Triantafillou A Haydock D, et al. The evolution of single lung transplantation for emphysema. 7 Thorac Cardiovasc Surg 1991;102:33-41.

21 Wakabayashi A, Brenner M, Kayaleh R, Berns MW, Barker SJ, et al. Thoracoscopic carbon dioxide laser treatment of bullous emphysema. Lancet 1991;337:881-3.

22 Little AG, Swain JA, Nino JJ, Prabhu RD, Schlacter MD, Barcia TC. Reduction pneumoplasty for emphysema. Ann Surg 1995;222:365-74.

23 Wakabayashi A. Thoracosopic laser pneumoplasty in the treatment of diffuse bullous emphysema. Ann Thorac Surg 1995;60:936-42.

24 Deslauriers J. Surgical management of COPD. Ann Thorac Surg 1995; 60:873-4.

25 Zenati M, Keenan RJ, Landreneau RJ, Paradis IL, Ferson PF, Griffith BP. Lung reduction as a bridge to lung transplantation in pulmonary emphysema. Ann Thorac Surg 1995;59:1581-3.

26 Nisar M, Walshaw MJ, Earis JE, Pearson MG, Calverley PMA. Assessment of reversibility of airway obstruction in patients with chronic obstructive airways disease. Thorax 1990;45:190-4.

27 Corris PA, Neville E, Nariman S, Gibson GJ. Dose response study of inhaled salbutamol powder in chronic airflow obstruction. Thorax 1983;38:292-6.

28 Hay JG, Stone P, Carter J, Church S, Eyre-Brook A, et al. Bronchodilator reversibility, exercise performance and breathlessness in stable chronic obstructive pulmonary disease. Eur Respir f 1992;5:659-64.

29 McGavin CR, Gupta SP, McHardy GJR. Twelve minute walking test for assessing disability in chronic bronchitis. $B M \mathcal{f} 1976$;i:822-3.

30 Spiro SG, Hahn HL, Edwards RHT, Pride NB. An analysis of the physiological strain of submaximal exercise in patients with chronic obstructive bronchitis. Thorax 1975;30:415-25.

31 Dillard TA, Hnatiuk OW, McCumber R. Maximum voluntary ventilation. Spirometric determinants in chronic obstructive pulmonary disease patients and normal subjects. Am Rev Respir Dis 1993;147: $870-5$.

32 Bradley TD, Chartrand DA, Fitting JW, Killian J, Grassino A. The relation of inspiratory effort sensation to fatiguing patterns of the diaphragm. Am Rev Respir Dis 1986;134:1119-24.

33 Clague JE, Carter J, Pearson MG, Calverley PMA. Physiological determinants of inspiratory efforet sensation during $\mathrm{CO}_{2}$ rebreathing in normal subjects. Clin Sci 1993;85:637-42.

34 LeBlanc P, Bowie DM, Summers E, Jones NL, Killian KJ. Breathlessness and exercise in patients with cardiorespiratory disease. Am Rev Respir Dis 1986;133:21-5.

35 O'Donnell DE, Webb KA. Exertional breathlessness in patients with chronic airflow limitation. Am Rev Respir Dis 1993;148:1351-7.

36 Horton R. Surgical research or comic opera: questions but few answers. Lancet 1996;347:984-5.

37 Gaissert HA, Trulock EP, Cooper JD, Sundarasen RS, Patterson GA. Comparison of early results after volume reduction or lung transplantation for COPD. $₹$ Thorac Cardiovasc Surg 1996;111:296-307.

38 Keenan RJ, Landreneau RJ, Sciurba FC, Ferson PF, Holbert JM, Brown MJ, et al. Unilateral thoracosopic surgical approach for diffuse emphysema. I Thorac Cardiovasc Surg 1996;111:308-16.

39 McKenna RJ, Brenner M, Gelb AF, Mullin M, Singh N, Peters H, et al. A randomised prospective trial of stapled lung reduction versus laser bullectomy for diffuse emphysema. $\mathcal{F}$ Thorac Cardiovasc Surg 1996;111:317-22.

40 Hogg JC, Nepszy SJ, Macklen PT, Thurlbeck WM. Elastic properties of the centrilobular emphysematous space. $\mathcal{F}$ Clin Invest 1969;48: 1306-12.

41 Anthonisen NR, Connell JE, Kiley JP, Altose MD, Bailey WC, et al. Effects of smoking intervention and the use of an inhaled anticholinergic bronchodilator on the rate of decline of $\mathrm{FEV}_{1} . \Im A M A$ 1994;272:1497-505.

42 Cooper JD, Lefrak. Is volume reduction surgery appropriate in the treatment of emphysema? Yes. Am $\mathcal{F}$ Respir Crit Care Med 1996;153: 1201-4.

43 Benditt JO, Albert RK. Lung reduction surgery: great expectations and a cautionary note. Chest 1995;107:297-8.

44 Rusch VM. Lung reduction surgery: a true advance? 7 Thorac Cardiovasc Surg 1996;111:193-5.

45 Make BJ. Is volume reduction surgery appropriate in the treatment of emphysema? No. Am $\mathcal{F}$ Respir Crit Care Med 1996;156:1205-7. 